\title{
A fixed point theorem for Meir-Keeler type contraction via Gupta-Saxena expression
}

\author{
Najeh Redjel ${ }^{1,2}$, Abdelkader Dehici $^{1,2}$ and İnci M Erhan ${ }^{3^{*}}$
}

\section{"Correspondence:}

inci.erhan@atilim.edu.tr

${ }^{3}$ Department of Mathematics,

Atilim University, İncek, Ankara, 06836, Turkey

Full list of author information is

available at the end of the article

\begin{abstract}
In this paper, following the idea of Samet et al. (J. Nonlinear. Sci. Appl. 6:162-169, 2013), we establish a new fixed point theorem for a Meir-Keeler type contraction via Gupta-Saxena rational expression which enables us to extend and generalize their main result (Gupta and Saxena in Math. Stud. 52:156-158, 1984). As an application we derive some fixed points of mappings of integral type.
\end{abstract}

MSC: $47 \mathrm{H} 10 ; 54 \mathrm{H} 25$

Keywords: complete metric space; fixed point; Meir-Keeler mapping; Gupta-Saxena rational expression

\section{Introduction}

It is well known that the contraction mapping principle of Banach [1] was the starting point of great discoveries and advances in mathematics, in particular in nonlinear analysis. This principle was the subject of several extensions by means of various generalized contractions (see, for example, [2-10]). Among the most relevant results in this direction one can give that of Meir and Keeler [11] who proved the following fixed point result.

Theorem 1.1 Let $(X, d)$ be a complete metric space and let $f$ be a mapping from $X$ into itself satisfying the following condition:

$$
\forall \epsilon>0, \exists \delta(\epsilon)>0 \quad \text { such that } \quad \epsilon \leq d(x, y)<\epsilon+\delta(\epsilon) \quad \Longrightarrow \quad d(f(x), f(y))<\epsilon .
$$

Then $f$ has a unique fixed point $u \in X$. Moreover, for all $x \in X$, the sequence $\left\{f^{n}(x)\right\}$ converges to $u$.

As pointed out in [11], it is easy to observe that the conclusion of Banach theorem holds for the contraction in Theorem 1.1 which is called a strict contraction, that is, it satisfies

$$
d(f(x), f(y))<d(x, y) \quad \text { for } x \neq y .
$$

In 1984, Gupta and Saxena proved the following fixed point result.

(c) 2015 Redjel et al. This article is distributed under the terms of the Creative Commons Attribution 4.0 International License (http://creativecommons.org/licenses/by/4.0/), which permits unrestricted use, distribution, and reproduction in any medium, provided you give appropriate credit to the original author(s) and the source, provide a link to the Creative Commons license, and indicate if changes were made. 
Theorem 1.2 Let $(X, d)$ be a complete metric space and let $f$ be a continuous mapping from $X$ into itself satisfying

$$
d(f(x), f(y)) \leq \alpha_{1} \frac{(1+d(x, f(x))) d(y, f(y))}{1+d(x, y)}+\alpha_{2} \frac{d(x, f(x)) d(y, f(y))}{d(x, y)}+\alpha_{3} d(x, y)
$$

for all $x, y \in X, x \neq y$, where $\alpha_{1}, \alpha_{2}, \alpha_{3}$ are constants with $\alpha_{1}, \alpha_{2}, \alpha_{3}>0$ and $\alpha_{1}+\alpha_{2}+\alpha_{3}<1$. Then $f$ has a unique fixed point $u \in X$. Moreover, for all $x \in X$, the sequence $\left\{f^{n}(x)\right\}$ converges to $u$.

For more details on this theorem, we refer, e.g., to $[12,13]$.

In this paper, we establish a new fixed point theorem of Meir-Keeler type involving Gupta-Saxena expression which extends Theorem 1.2 in the case where $\left.\alpha_{1}, \alpha_{2}, \alpha_{3} \in\right] 0, \frac{1}{3}[$. We also apply our theoretical results to contractions of integral type.

\section{Main results}

Our main result is the following theorem.

Theorem 2.1 Let $(X, d)$ be a complete metric space and let $f: X \rightarrow X$ be a continuous mapping. Assume that the following condition holds.

For any $\epsilon>0$, there exists $\delta(\epsilon)>0$ such that

$$
\begin{aligned}
3 \epsilon & \leq \frac{(1+d(x, f(x))) d(y, f(y))}{1+d(x, y)}+\frac{d(x, f(x)) d(y, f(y))}{d(x, y)}+d(x, y)<3 \epsilon+\delta(\epsilon) \\
& \Longrightarrow \quad d(f(x), f(y))<\epsilon
\end{aligned}
$$

for all $x, y \in X$ with $x \neq y$. Then $f$ has a unique fixed point $u \in X$. Moreover, $\lim _{n \rightarrow \infty} f^{n}\left(x_{0}\right)=$ $u$ for any $x_{0} \in X$.

Proof It is easy to observe that condition (1) implies that

$$
\begin{aligned}
& \text { for } x \neq y \text { or } f(y) \neq y \text {, } \\
& \qquad d(f(x), f(y))<\frac{1}{3}\left[\frac{(1+d(x, f(x))) d(y, f(y))}{1+d(x, y)}+\frac{d(x, f(x)) d(y, f(y))}{d(x, y)}+d(x, y)\right] .
\end{aligned}
$$

Let $x_{0} \in X$ and consider the sequence $\left\{x_{n}\right\}=\left\{f^{n}\left(x_{0}\right)\right\}_{n \geq 0}$. We will prove that $\left\{x_{n}\right\}$ is a Cauchy sequence in $X$. If there exists $l_{0} \in \mathbb{N}$ such that $x_{l_{0}}=x_{l_{0+1}}$, then clearly $x_{l_{0}}$ is a fixed point of $f$. Now assume that $x_{k} \neq x_{k+1}$ for all $k \in \mathbb{N}$. Define

$$
s_{n}=d\left(x_{n}, x_{n+1}\right), \quad \forall n \in \mathbb{N}
$$

Following (2), we obtain that

$$
\begin{aligned}
s_{n} & =d\left(f\left(x_{n-1}\right), f\left(x_{n}\right)\right) \\
& <\frac{1}{3} \frac{\left(1+d\left(x_{n-1}, x_{n}\right)\right) d\left(x_{n}, x_{n+1}\right)}{1+d\left(x_{n-1}, x_{n}\right)}+\frac{1}{3} \frac{d\left(x_{n-1}, x_{n}\right) d\left(x_{n}, x_{n+1}\right)}{d\left(x_{n-1}, x_{n}\right)}+\frac{1}{3} d\left(x_{n-1}, x_{n}\right) \\
& =\frac{2}{3} d\left(x_{n}, x_{n+1}\right)+\frac{1}{3} d\left(x_{n-1}, x_{n}\right)=\frac{2}{3} s_{n}+\frac{1}{3} s_{n-1} .
\end{aligned}
$$


This results in

$$
s_{n}<s_{n-1}, \quad \forall n \in \mathbb{N},
$$

that is, the sequence $\left\{s_{n}\right\}$ is decreasing. Then $s_{n}$ converges to some $s \geq 0$; and, moreover, $s_{n} \geq s, \forall n \geq 0$. We also have $2 s_{n}+s_{n-1} \rightarrow 3 s$ as $n \rightarrow+\infty$. From (1), if $s>0$, there exists $\delta(s)>0$ such that

$$
3 s \leq 2 s_{n}+s_{n-1}<3 s+\delta(s)
$$

implies

$$
d\left(f\left(x_{n-1}\right), f\left(x_{n}\right)\right)=d\left(x_{n}, x_{n+1}\right)=s_{n}<s,
$$

which contradicts $s_{n} \geq s$. Thus, we deduce that

$$
s_{n} \rightarrow 0 \quad \text { as } n \rightarrow+\infty
$$

Now, let

$$
\delta^{\prime}(\epsilon)=\min \left\{\delta\left(\frac{\epsilon}{7}\right), \frac{\epsilon}{7}, 1\right\} .
$$

By the convergence of the sequence $\left\{d\left(x_{n}, x_{n+1}\right)\right\}$ to 0 , there exists $k_{0} \in \mathbb{N}$ such that

$$
d\left(x_{l}, x_{l+1}\right)<\frac{\delta^{\prime}(\epsilon)}{6}, \quad \forall l \geq k_{0} .
$$

Now, we define the set $\Omega$ by

$$
\Omega=\left\{x_{p} \mid p \geq k_{0}, d\left(x_{p}, x_{k_{0}}\right)<\frac{3 \epsilon}{7}+\frac{\delta^{\prime}(\epsilon)}{3}\right\} .
$$

We will prove that

$$
f(\Omega) \subset \Omega .
$$

Clearly, for $\gamma \in \Omega$, there exists $p \geq k_{0}$ such that $\gamma=x_{p}$ and $d\left(x_{p}, x_{k_{0}}\right)<\frac{3 \epsilon}{7}+\frac{\delta^{\prime}(\epsilon)}{3}$. If $p=k_{0}$, we have $f(\gamma)=x_{k_{0}+1} \in \Omega$ by (3). Then we will assume that $p>k_{0}$. We distinguish two cases as follows.

(1) First case: Assume that

$$
\frac{3 \epsilon}{7} \leq d\left(x_{p}, x_{k_{0}}\right)<\frac{3 \epsilon}{7}+\frac{\delta^{\prime}(\epsilon)}{3} .
$$

First, we will show that

$$
\begin{aligned}
\frac{\epsilon}{7} & \leq \frac{1}{3} \frac{\left(1+d\left(x_{p}, x_{p+1}\right)\right) d\left(x_{k_{0}}, x_{k_{0}+1}\right)}{1+d\left(x_{p}, x_{k_{0}}\right)}+\frac{1}{3} \frac{d\left(x_{p}, x_{p+1}\right) d\left(x_{k_{0}}, x_{k_{0}+1}\right)}{d\left(x_{p}, x_{k_{0}}\right)}+\frac{1}{3} d\left(x_{p}, x_{k_{0}}\right) \\
& <\frac{\epsilon}{7}+\frac{\delta^{\prime}(\epsilon)}{3} .
\end{aligned}
$$


From (5), we have

$$
\begin{aligned}
\frac{\epsilon}{7} & \leq \frac{1}{3} d\left(x_{p}, x_{k_{0}}\right) \\
& \leq \frac{1}{3} \frac{\left(1+d\left(x_{p}, x_{p+1}\right)\right) d\left(x_{k_{0}}, x_{k_{0}+1}\right)}{1+d\left(x_{p}, x_{k_{0}}\right)}+\frac{1}{3} \frac{d\left(x_{p}, x_{p+1}\right) d\left(x_{k_{0}}, x_{k_{0}+1}\right)}{d\left(x_{p}, x_{k_{0}}\right)}+\frac{1}{3} d\left(x_{p}, x_{k_{0}}\right) .
\end{aligned}
$$

Moreover, by using (3) and (5), we get

$$
\begin{aligned}
\frac{1}{3} & \frac{\left(1+d\left(x_{p}, x_{p+1}\right)\right) d\left(x_{k_{0}}, x_{k_{0}+1}\right)}{1+d\left(x_{p}, x_{k_{0}}\right)}+\frac{1}{3} \frac{d\left(x_{p}, x_{p+1}\right) d\left(x_{k_{0}}, x_{k_{0}+1}\right)}{d\left(x_{p}, x_{k_{0}}\right)}+\frac{1}{3} d\left(x_{p}, x_{k_{0}}\right) \\
& \leq \frac{1}{3} d\left(x_{k_{0}}, x_{k_{0}+1}\right)+\frac{2}{3} \frac{d\left(x_{k_{0}}, x_{k_{0}+1}\right) d\left(x_{p}, x_{p+1}\right)}{d\left(x_{p}, x_{k_{0}}\right)}+\frac{1}{3} d\left(x_{p}, x_{k_{0}}\right) \\
& <\frac{1}{3} \frac{\delta^{\prime}(\epsilon)}{6}+\frac{2}{3} d\left(x_{p}, x_{p+1}\right)+\frac{1}{3} d\left(x_{p}, x_{k_{0}}\right) \\
& <\frac{\delta^{\prime}(\epsilon)}{18}+\frac{2}{3} \frac{\delta^{\prime}(\epsilon)}{6}+\frac{1}{3}\left(\frac{3 \epsilon}{7}+\frac{\delta^{\prime}(\epsilon)}{3}\right) \\
& =\frac{\epsilon}{7}+\frac{5 \delta^{\prime}(\epsilon)}{18} \\
& <\frac{\epsilon}{7}+\frac{\delta^{\prime}(\epsilon)}{3} .
\end{aligned}
$$

Then we obtain

$$
\begin{aligned}
& \frac{1}{3} \frac{\left(1+d\left(x_{p}, x_{p+1}\right)\right) d\left(x_{k_{0}}, x_{k_{0}+1}\right)}{1+d\left(x_{p}, x_{k_{0}}\right)}+\frac{1}{3} \frac{d\left(x_{p}, x_{p+1}\right) d\left(x_{k_{0}}, x_{k_{0}+1}\right)}{d\left(x_{p}, x_{k_{0}}\right)}+\frac{1}{3} d\left(x_{p}, x_{k_{0}}\right) \\
& <\frac{\epsilon}{7}+\frac{\delta^{\prime}(\epsilon)}{3} .
\end{aligned}
$$

From (7) and (8), we deduce that (6) is satisfied. In this case, the inequality

$$
\begin{aligned}
\frac{3 \epsilon}{7} & \leq \frac{\left(1+d\left(x_{p}, f\left(x_{p}\right)\right)\right) d\left(x_{k_{0}}, f\left(x_{k_{0}}\right)\right)}{1+d\left(x_{p}, x_{k_{0}}\right)}+\frac{d\left(x_{p}, f\left(x_{p}\right)\right) d\left(x_{k_{0}}, f\left(x_{k_{0}}\right)\right)}{d\left(x_{p}, x_{k_{0}}\right)}+d\left(x_{p}, x_{k_{0}}\right) \\
& <\frac{3 \epsilon}{7}+\delta^{\prime}(\epsilon)
\end{aligned}
$$

implies by (1) that

$$
d\left(f\left(x_{p}\right), f\left(x_{k_{0}}\right)\right)<\frac{\epsilon}{7}
$$

Now, using the triangular inequality together with (3) and (9), we obtain that

$$
\begin{aligned}
d\left(f\left(x_{p}\right), x_{k_{0}}\right) & \leq d\left(f\left(x_{p}\right), f\left(x_{k_{0}}\right)\right)+d\left(f\left(x_{k_{0}}\right), x_{k_{0}}\right) \\
& <\frac{\epsilon}{7}+\frac{\delta^{\prime}(\epsilon)}{6} \\
& <\frac{3 \epsilon}{7}+\frac{\delta^{\prime}(\epsilon)}{3} .
\end{aligned}
$$

This implies that $f(\gamma)=f\left(x_{p}\right)=x_{p+1} \in \Omega$. 
(2) Second case: Suppose that

$$
d\left(x_{p}, x_{k_{0}}\right)<\frac{3 \epsilon}{7}
$$

From (2), we infer that

$$
\begin{aligned}
d\left(f\left(x_{p}\right), x_{k_{0}}\right) \leq & d\left(f\left(x_{p}\right), f\left(x_{k_{0}}\right)\right)+d\left(f\left(x_{k_{0}}\right), x_{k_{0}}\right) \\
< & \frac{1}{3} \frac{\left(1+d\left(x_{p}, x_{p+1}\right)\right) d\left(x_{k_{0}}, x_{k_{0}+1}\right)}{1+d\left(x_{p}, x_{k_{0}}\right)}+\frac{1}{3} \frac{d\left(x_{p}, x_{p+1}\right) d\left(x_{k_{0}}, x_{k_{0}+1}\right)}{d\left(x_{p}, x_{k_{0}}\right)} \\
& +\frac{1}{3} d\left(x_{p}, x_{k_{0}}\right)+d\left(x_{k_{0}+1}, x_{k_{0}}\right) \\
\leq & \frac{1}{3} \frac{d\left(x_{p}, x_{p+1}\right) d\left(x_{k_{0}}, x_{k_{0}+1}\right)}{1+d\left(x_{p}, x_{k_{0}}\right)}+\frac{1}{3} \frac{d\left(x_{p}, x_{p+1}\right) d\left(x_{k_{0}}, x_{k_{0}+1}\right)}{d\left(x_{p}, x_{k_{0}}\right)} \\
& +\frac{1}{3} d\left(x_{p}, x_{k_{0}}\right)+\frac{4}{3} d\left(x_{k_{0}+1}, x_{k_{0}}\right) .
\end{aligned}
$$

On the other hand, from (3) we have

$$
\frac{d\left(x_{k_{0}}, x_{k_{0}+1}\right)}{1+d\left(x_{p}, x_{k_{0}}\right)} \leq d\left(x_{k_{0}}, x_{k_{0}+1}\right)<\frac{\delta^{\prime}(\epsilon)}{6}<1
$$

We consider the following two situations.

(i) If $d\left(x_{k_{0}}, x_{k_{0}+1}\right) \leq d\left(x_{k_{0}}, x_{p}\right)$, then (11) gives

$$
d\left(f\left(x_{p}\right), x_{k_{0}}\right)<\frac{1}{3} d\left(x_{p}, x_{p+1}\right)+\frac{1}{3} d\left(x_{p}, x_{p+1}\right)+\frac{1}{3} d\left(x_{p}, x_{k_{0}}\right)+\frac{4}{3} d\left(x_{k_{0}+1}, x_{k_{0}}\right) .
$$

From (3) and (10), we deduce that

$$
\begin{aligned}
d\left(f\left(x_{p}\right), x_{k_{0}}\right) & <\frac{2}{3}\left(\frac{\delta^{\prime}(\epsilon)}{6}\right)+\frac{1}{3}\left(\frac{3 \epsilon}{7}\right)+\frac{4}{3}\left(\frac{\delta^{\prime}(\epsilon)}{6}\right) \\
& =\frac{\delta^{\prime}(\epsilon)}{3}+\frac{\epsilon}{7} \\
& <\frac{\delta^{\prime}(\epsilon)}{3}+\frac{3 \epsilon}{7} .
\end{aligned}
$$

(ii) If $d\left(x_{k_{0}}, x_{k_{0}+1}\right)>d\left(x_{k_{0}}, x_{p}\right)$, then

$$
\begin{aligned}
d\left(f\left(x_{p}\right), x_{k_{0}}\right) & \leq d\left(x_{p+1}, x_{p}\right)+d\left(x_{p}, x_{k_{0}}\right) \\
& <d\left(x_{p+1}, x_{p}\right)+d\left(x_{k_{0}}, x_{k_{0}+1}\right) \\
& <\frac{\delta^{\prime}(\epsilon)}{6}+\frac{\delta^{\prime}(\epsilon)}{6} \\
& =\frac{\delta^{\prime}(\epsilon)}{3} \\
& <\frac{\delta^{\prime}(\epsilon)}{3}+\frac{3 \epsilon}{7} .
\end{aligned}
$$


In both situations (i) and (ii), we have $f(\gamma)=f\left(x_{p}\right)=x_{p+1} \in \Omega$. Thus, (4) holds and

$$
d\left(x_{m}, x_{k_{0}}\right)<\frac{3 \epsilon}{7}+\frac{\delta^{\prime}(\epsilon)}{3}, \quad \forall m>k_{0} .
$$

Now, $\forall m, n \in \mathbb{N}$ satisfying $m>n>k_{0}$, by (12), we have

$$
d\left(x_{m}, x_{n}\right) \leq d\left(x_{m}, x_{k_{0}}\right)+d\left(x_{n}, x_{k_{0}}\right)<\frac{6 \epsilon}{7}+\delta^{\prime}(\epsilon)<\frac{6 \epsilon}{7}+\frac{\epsilon}{7}=\epsilon .
$$

Therefore, $\left\{x_{n}\right\}$ is a Cauchy sequence in $X$.

Since $(X, d)$ is a complete metric space, then there exists $u \in X$ such that $x_{n} \rightarrow u$ as $n \rightarrow+\infty$. The fact that $x_{n+1}=f\left(x_{n}\right)$ and the continuity of $f$ imply that $u=f(u)$, that is, $u$ is a fixed point of $f$.

To show the uniqueness, we assume that $u^{\prime}$ is another fixed point of $f$. From (2) it follows that

$$
\begin{aligned}
d\left(u, u^{\prime}\right) & =d\left(f(u), f\left(u^{\prime}\right)\right)<\frac{1}{3}\left(\frac{1+d(u, u) d\left(u^{\prime}, u^{\prime}\right)}{1+d\left(u, u^{\prime}\right)}\right)+\frac{1}{3} \frac{d(u, u) d\left(u^{\prime}, u^{\prime}\right)}{d\left(u, u^{\prime}\right)}+\frac{1}{3} d\left(u, u^{\prime}\right) \\
& =\frac{1}{3} d\left(u, u^{\prime}\right),
\end{aligned}
$$

which is a contradiction. This proves the uniqueness of the fixed point and completes the proof of the theorem.

Now, we show that the result of Gupta and Saxena [12], where $\left.\alpha_{1}, \alpha_{2}, \alpha_{3} \in\right] 0, \frac{1}{3}[$, is a particular case of Theorem 2.1.

Corollary 2.2 (Gupta and Saxena [12]) Let $(X, d)$ be a complete metric space and $f$ be a continuous mapping from $X$ into itself. Assume that $f$ satisfies

$$
\begin{aligned}
& \forall x, y \in X, x \neq y, \\
& \quad d(f(x), f(y)) \leq k\left(\frac{(1+d(x, f(x))) d(y, f(y))}{1+d(x, y)}+\frac{d(x, f(x)) d(y, f(y))}{d(x, y)}+d(x, y)\right),
\end{aligned}
$$

where $k \in] 0, \frac{1}{3}$ [ is a constant. Then $f$ has a unique fixed point $u \in X$. Moreover, $\forall x \in X$, the sequence $\left\{f^{n}(x)\right\}$ converges to $u$.

Proof Let $\epsilon>0$. If we take

$$
\delta(\epsilon)=\epsilon\left(\frac{1}{k}-3\right),
$$

then, whenever

$$
\begin{aligned}
& 3 \epsilon \leq \frac{(1+d(x, f(x))) d(y, f(y))}{1+d(x, y)}+\frac{d(x, f(x)) d(y, f(y))}{d(x, y)}+d(x, y)<3 \epsilon+\delta, \\
& d(f(x), f(y)) \leq k\left(\frac{(1+d(x, f(x))) d(y, f(y))}{1+d(x, y)}+\frac{d(x, f(x)) d(y, f(y))}{d(x, y)}+d(x, y)\right) \\
& <k(3 \epsilon+\delta(\epsilon))
\end{aligned}
$$




$$
\begin{aligned}
& =3 k \epsilon+k \delta(\epsilon) \\
& =3 k \epsilon+\frac{k \epsilon}{k}-3 k \epsilon \\
& =\epsilon .
\end{aligned}
$$

Notice that since $k<\frac{1}{3}$, then $\frac{\epsilon}{k}>3 \epsilon$. Thus the condition (1) of Theorem 2.1 is satisfied, which completes the proof.

Notice that the contraction mapping of Gupta and Saxena is a not a strict contraction, but $k$-contraction. Therefore, Theorem 2.1 is an extension of Gupta-Saxena result.

\section{Applications}

In this section, following the idea of Samet et al. [14], we will give an integral version of Gupta-Saxena result.

We start with the following theorem.

Theorem 3.1 Let $(X, d)$ be a metric space and let $f$ be a self-mapping defined on X. Assume that there exists a function $\rho$ from $[0,+\infty$ [ into itself satisfying the following:

(i) $\rho(0)=0$ and $\rho(t)>0$ for every $t>0$;

(ii) $\rho$ is nondecreasing and right continuous;

(iii) for every $\epsilon>0$, there exists $\delta(\epsilon)>0$ such that

$$
\begin{aligned}
3 \epsilon & \leq \rho\left(\frac{(1+d(x, f(x))) d(y, f(y))}{1+d(x, y)}+\frac{d(x, f(x)) d(y, f(y))}{d(x, y)}+d(x, y)\right)<3 \epsilon+\delta(\epsilon) \\
& \Longrightarrow \quad \rho(3 d(f(x), f(y)))<3 \epsilon
\end{aligned}
$$

for all $x, y \in X$ with $x \neq y$.

Then (1) is satisfied.

Proof Fix $\epsilon>0$. Since $\rho(3 \epsilon)>0$, by (iii), for $\rho(3 \epsilon)$ there exists $\theta>0$ such that

$$
\begin{aligned}
& \rho(3 \epsilon) \leq \rho\left(\frac{(1+d(x, f(x))) d(y, f(y))}{1+d(x, y)}+\frac{d(x, f(x)) d(y, f(y))}{d(x, y)}+d(x, y)\right)<\rho(3 \epsilon)+\theta \\
& \Longrightarrow \quad \rho(3 d(f(x), f(y)))<\rho(3 \epsilon) .
\end{aligned}
$$

From the right continuity of $\rho$, there exists $\delta>0$ such that $\rho(3 \epsilon+\delta)<\rho(3 \epsilon)+\theta$. Fix $x, y \in X$, $x \neq y$ such that

$$
3 \epsilon \leq \frac{(1+d(x, f(x))) d(y, f(y))}{1+d(x, y)}+\frac{d(x, f(x)) d(y, f(y))}{d(x, y)}+d(x, y)<3 \epsilon+\delta .
$$

Since $\rho$ is nondecreasing, we deduce

$$
\begin{aligned}
\rho(3 \epsilon) & \leq \rho\left(\frac{(1+d(x, f(x))) d(y, f(y))}{1+d(x, y)}+\frac{d(x, f(x)) d(y, f(y))}{d(x, y)}+d(x, y)\right) \\
& <\rho(3 \epsilon+\delta)<\rho(3 \epsilon)+\theta .
\end{aligned}
$$


Then, by (14), we have

$$
\rho(3 d(f(x), f(y)))<\rho(3 \epsilon)
$$

which implies that $d(f(x), f(y))<\epsilon$. Then (1) is satisfied and this completes the proof.

Now, we denote by $\Xi$ the set of all mappings $h:[0,+\infty[\rightarrow[0,+\infty[$ satisfying:

(i) $h$ is continuous and nondecreasing;

(ii) $h(0)=0$ and $h(t)>0$ for all $t>0$.

Corollary 3.2 Let $(X, d)$ be a metric space and let $f$ be a mapping from $X$ into itself. Assume that for each $\epsilon>0$, there exists $\delta(\epsilon)$ such that

$$
\begin{aligned}
3 \epsilon & \leq h\left(\frac{(1+d(x, f(x))) d(y, f(y))}{1+d(x, y)}+\frac{d(x, f(x)) d(y, f(y))}{d(x, y)}+d(x, y)\right)<3 \epsilon+\delta(\epsilon) \\
& \Longrightarrow h(3 d(f(x), f(y)))<3 \epsilon
\end{aligned}
$$

for all $x, y \in X$, with $x \neq y$, where $h \in \Xi$ is a given function. Then (1) is satisfied.

Proof This follows immediately from Theorem 3.1 since every continuous function $h$ : $[0,+\infty[\rightarrow[0,+\infty[$ is right continuous.

As a consequence of this corollary, we have another result.

Corollary 3.3 Let $(X, d)$ be a metric space and let $f$ be a mapping from $X$ into itself. Let $\varphi$ be a locally integrable function from $\left[0,+\infty\right.$ [ into itself such that $\int_{0}^{t} \varphi(s) d s>0$ for all $t>0$. Assume that for each $\epsilon>0$ there exists $\delta(\epsilon)$ such that

$$
\begin{aligned}
3 \epsilon & \leq \int_{0}^{\frac{(1+d(x, f(x))) d(y, f(y))}{1+d(x, y)}+\frac{d(x, f(x)) d(y, f(y))}{d(x, y)}+d(x, y)} \varphi(t) d t<3 \epsilon+\delta(\epsilon) \\
& \Longrightarrow \int_{0}^{3 d(f(x), f(y))} \varphi(t) d t<3 \epsilon .
\end{aligned}
$$

Then (1) is satisfied.

Now, we are able to obtain an integral version of Gupta-Saxena result.

Corollary 3.4 Let $(X, d)$ be a complete metric space and let $f$ be a continuous mapping from $X$ into itself. Let $\varphi$ be a locally integrable function from $[0,+\infty[$ into itself such that $\int_{0}^{t} \varphi(s) d s>0$ for all $t>0$. Assume that $f$ satisfies the following condition.

For all $x, y \in X, x \neq y$,

$$
\int_{0}^{3 d(f(x), f(y))} \varphi(t) d t \leq \mu \int_{0}^{\frac{(1+d(x, f(x))) d((y, f(y))}{1+d(x, y)}+\frac{d(x, f(x)) d(y, f(y))}{d(x, y)}+d(x, y)} \varphi(t) d t
$$

where $\mu \in] 0,1[$. Then $f$ has a unique fixed point $u \in X$. Moreover, for any $x \in X$, the sequence $\left\{f^{n}(x)\right\}$ converges to $u$. 
Proof Let $\epsilon>0$. It is easy to observe that (15) is satisfied for $\delta(\epsilon)=3 \epsilon\left(\frac{1}{\mu}-1\right)$. Then (1) holds and this completes the proof.

Remark 3.5 Note that the result of Corollary 2.2 can be established from Corollary 3.4 by taking $\varphi \equiv 1$ and $\mu=3 k, k \in] 0, \frac{1}{3}$ [. Clearly, for this choice, (16) becomes

$$
d(f(x), f(y)) \leq k\left(\frac{(1+d(x, f(x))) d(y, f(y))}{1+d(x, y)}+\frac{d(x, f(x)) d(y, f(y))}{d(x, y)}+d(x, y)\right),
$$

which is exactly the contractive condition of Corollary 2.2 .

\section{Competing interests}

The authors declare that they have no competing interests.

\section{Authors' contributions}

All authors contributed equally and significantly in writing this article. All authors read and approved the final manuscript.

\section{Author details}

${ }^{1}$ Laboratory of Informatics and Mathematics, University of Souk-Ahras, P.O. Box 1553, Souk-Ahras, 41000, Algeria.

${ }^{2}$ Department of Mathematics, University of Constantine 1, Constantine, 25000, Algeria. ${ }^{3}$ Department of Mathematics, Atilim University, Incek, Ankara, 06836, Turkey.

\section{Acknowledgements}

This work was elaborated within the framework of the scientific stay of the first two authors at Atılım University (Turkey). They thank all the staff of the Department of Mathematics, Atılım University and, in particular, Professor Karapınar for offering a pleasant environment of work and for his helpful discussions.

Received: 9 March 2015 Accepted: 23 June 2015 Published online: 15 July 2015

\section{References}

1. Banach, S: Sur les opérations dans les ensembles abstraits et leur application aux équations intégrales. Fundam. Math. 3, 133-181 (1922)

2. Ali, MU, Kamran, T, Karapınar, E: Fixed points of $\alpha-\psi$-contractive type mappings in uniform spaces. Fixed Point Theory Appl. 2014, 150 (2014)

3. Ali, MU, Kamran, T, Shahzad, N: Best proximity point for $\alpha$ - $\psi$-proximal contractive multimaps. Abstr. Appl. Anal. 2014, Article ID 181598 (2014)

4. Berinde, V: Iterative Approximation of Fixed Points. Editura Efemeride, Baia Mare (2002)

5. Branciari, A: A fixed point theorem for mappings satisfying a general contractive condition of integral type. Int. J. Math. Math. Sci. 29(9), 531-536 (2002)

6. Karapınar, E, Samet, B: Generalized $\alpha-\psi$ contractive type mappings and related fixed point theorems with applications. Abstr. Appl. Anal. 2012, Article ID 973486 (2012)

7. Kiran, Q, Ali, MU, Kamran, T: Generalization of Mizoguchi-Takahashi type contraction and related fixed point theorems. J. Inequal. Appl. 2014, 458 (2014)

8. Latif, A, Gordji, ME, Karapınar, E, Sintunavarat, W: Fixed point results for generalized $(\alpha, \psi)$-Meir-Keeler contractive mappings and applications. J. Inequal. Appl. 2014, 68 (2014)

9. Popa, V, Mocanu, M: Altering distance and common fixed points under implicit relations. Hacet. J. Math. Stat. 38(3), 329-337 (2009)

10. Redjel, N: On some extensions of Banach's contraction principle and application to the convergence of some iterative processes. Adv. Fixed Point Theory 4(4), 555-570 (2014)

11. Meir, A, Keeler, E: A theorem on contraction mappings. J. Math. Anal. Appl. 28, 326-329 (1969)

12. Gupta, AN, Saxena, A: A unique fixed point theorem in metric spaces. Math. Stud. 52, 156-158 (1984)

13. Rhoades, BE: Proving fixed point theorems using general principles. Indian J. Pure Appl. Math. 27(8), 741-770 (1996)

14. Samet, B, Vetro, C, Yazidi, H: A fixed point theorem for a Meir-Keeler type contraction through rational expression. J. Nonlinear Sci. Appl. 6, 162-169 (2013) 